\title{
Dipodal, Tripodal, and Discoidal Coordination Modes of Kemp's
}

\section{Triacid Anions}

\author{
Jack Harrowfield*[a] and Pierre Thuéry*[b]

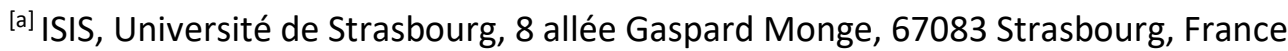 \\ E-mail: harrowfield@unistra.fr \\ https://isis.unistra.fr/fr/ \\ [b] Université Paris-Saclay, CEA, CNRS, NIMBE, 91191 Gif-sur-Yvette, France \\ E-mail: pierre.thuery@cea.fr \\ http://iramis.cea.fr/nimbe/
}

Keywords: Kemp's triacid / Metal cations / Carboxylic acids / Structure elucidation / Coordination networks

\begin{abstract}
In order to probe the conformational preferences of the anions of Kemp's triacid (cis, cis-1,3,5trimethyl-1,3,5-cyclohexanetricarboxylic acid, $\mathrm{H}_{3} \mathrm{kta}$ ) in their metal ion complexes, and their influence on the structures thereof, six complexes with widely different metal cations (alkali, alkaline-earth, 3d-block and actinide) were synthesized and crystallographically characterized. All these complexes crystallize as diperiodic assemblies, but with three different conformations of the $\mathrm{kta}^{3-} / \mathrm{Hkta}^{2-} / \mathrm{H}_{3} \mathrm{kta}$ ligands. Only the tripodal form, with the cyclohexyl ring in chair conformation and the three carboxylic/ate groups axial is found in $\left[\mathrm{Na}_{5}(\mathrm{kta})(\mathrm{Hkta})\left(\mathrm{H}_{2} \mathrm{O}\right)\right]$ (1), $\left[\mathrm{Sr}_{3}\left(\mathrm{H}_{3} \mathrm{kta}\right)(\mathrm{kta})_{2}\right]$ (2), $\left[\mathrm{Mn}_{3}(\mathrm{kta})_{2}\left(\mathrm{H}_{2} \mathrm{O}\right)_{3}\right](3)$, and $\left[\mathrm{Mn}\left(\mathrm{H}_{2} \mathrm{O}\right)_{6}\right]\left[\mathrm{Mn}_{5}(\mathrm{kta})_{4}\left(\mathrm{H}_{2} \mathrm{O}\right)_{4}\right]$ (4). Particularly notable are hexanuclear ring subunits formed around two ligands in $\mathbf{2}$. The tripodal form coexists with the discoidal one, with the ring in the chair conformation and the three carboxylate groups equatorial, in $\left[\mathrm{Mn}_{6}(\mathrm{kta})_{4}(\mathrm{nmp})_{3}\right](5)$, with $\mathrm{nmp}=\mathrm{N}$-methyl-2-pyrrolidone, which displays hexanuclear ring subunits. Finally, the so-called dipodal form, with the ring in boat conformation, two carboxylate groups axial and one equatorial, is only found in $\left[\mathrm{UO}_{2} \mathrm{Cs}(\mathrm{kta})\right](6)$, in which uranyl cations and ligands alone form a honeycomb assembly, the caesium cations being decorating species.
\end{abstract}




\section{Introduction}

The carboxylate group is a versatile coordinating unit known to variously adopt unidentate, chelate, bridging and chelate-bridging roles in a vast range of crystalline metal ion complexes. ${ }^{[1-4]}$ This versatility is enhanced in polycarboxylate species where multiple groups can be attached to frameworks varying from highly flexible polymethylene chains to extremely rigid polycyclic and aromatic entities, sometimes endowed with additional functionality, including chirality, and this has led to their widespread exploitation in the synthesis of coordination polymers and metal-organic frameworks. ${ }^{[5-10]}$ As an example of a source of a tricarboxylate system of high symmetry, Kemp's triacid, cis,cis-1,3,5-trimethyl1,3,5-cyclohexanetricarboxylic acid $\left(\mathrm{H}_{3} \mathrm{kta}\right)$ has been used to prepare a number of crystalline coordination complexes which have been characterized by crystal structure determinations. ${ }^{[11-18]}$ Interestingly, this number (23) is smaller than that (26) of those of structure determinations on just complexes of dicarboxylate ligands obtained by reactions of diamines with axially oriented carboxylic groups of Kemp's triacid to give bis(imide)dicarboxylates, ${ }^{[19-25]}$ a difference which, in our experience, possibly reflects the difficulty in general of obtaining suitable crystals of metal complexes of the simple triacid anions. Two factors influencing the nature of the species in a solution of Kemp's triacid and thus the composition of any crystalline material deposited are the degree of dissociation and the conformational equilibria involving the different anions. The acidity constants $\left(\mathrm{pK}_{a 1} 3.6\right.$, $\mathrm{pK}_{a 2} 6.2, \mathrm{pK}_{a 3} 7.3 ; 298 \mathrm{~K}, 0.15$ mol L-1 aqueous $\mathrm{NaClO}_{4}{ }^{[11]}$ ) for Kemp's triacid are sufficiently close for mixtures of anions to be present over a wide $\mathrm{pH}$ range. Even in the presence of a strong base ([NBu 4$] \mathrm{OH})$, Fe and $\mathrm{Mn}$ complexes, for example, were obtained with both $\mathrm{kta}^{3-}$ and $\mathrm{Hkta}^{2-}$ anions present in the crystal structures. ${ }^{[12,13]}$ On the basis of ${ }^{1} \mathrm{H}$ NMR spectroscopy in aqueous solution, ${ }^{[26]}$ both $\mathrm{H}_{2} \mathrm{kta}^{-}$and $\mathrm{Hkta}^{2-}$ were assigned a chair 
conformation with carboxyl/ate groups axial, while $\mathrm{kta}^{3-}$ was assigned a chair conformation with the carboxylate groups equatorial, corresponding to tripodal and discoidal arrays, respectively, of the coordinating groups. While what is seen in known structures ${ }^{[11-18]}$ does not reflect such a clear dichotomy, the dianionic ligand has only been found in the tripodal form $^{[11-13]}$ and the trianionic ligand has been found in both tripodal and discoidal conformations $^{[14-17]}$ as well as, somewhat unexpectedly, in a boat conformation with two carboxylate groups equatorial and one axial, ${ }^{[16]}$ a form we denote as dipodal (Scheme 1). As the discoidal form has only been found in complexes of very heavy metals ( $\mathrm{Pb}$ and $\mathrm{U}$ ) prepared under solvothermal conditions, it is unclear whether this is a consequence of the nature of the metal ions or of the particular method of synthesis. The present structural study of Kemp's triacid complexes of metal ions across a wide range of the Periodic Table provides some clarification of these issues.
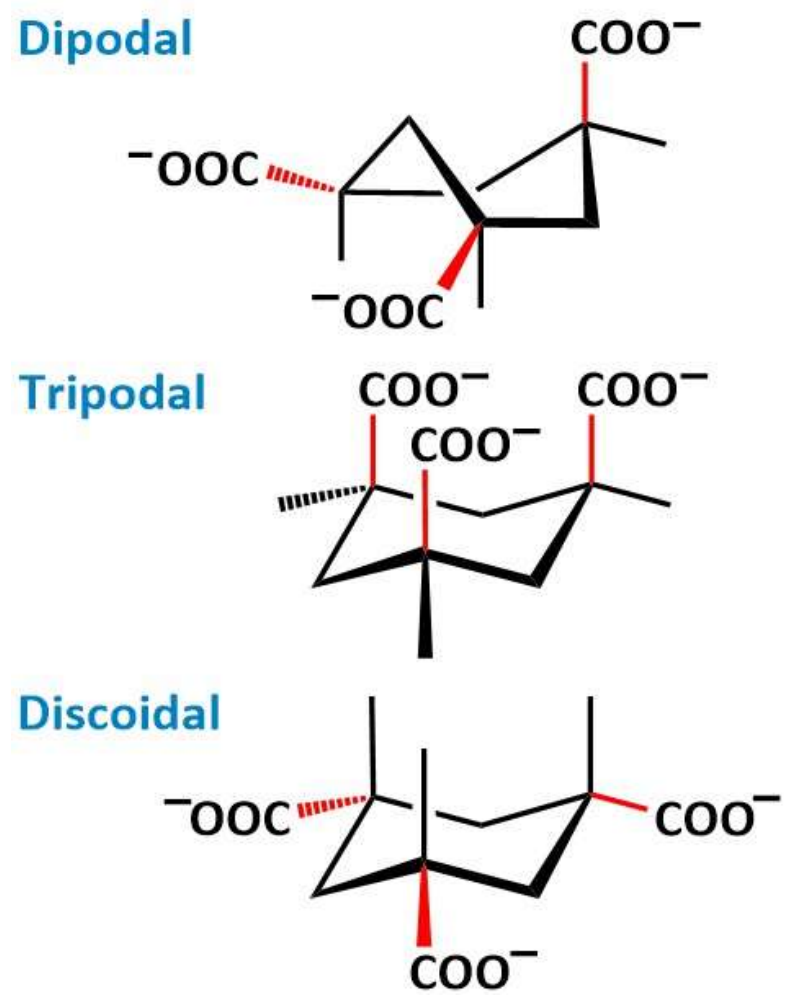

Scheme 1. The three conformations of $\mathrm{kta}^{3-}$ found in its metal ion complexes. 


\section{Results and Discussion}

The acidity constant values (cited above) for Kemp's triacid are such that at least the trianion would be expected to undergo a significant degree of hydrolysis in a pure aqueous solution under ambient conditions. This may explain why recrystallisation from water of material believed to be $\mathrm{Na}_{3} \mathrm{kta}$ provided the crystals characterised by their structure determination as $\left[\mathrm{Na}_{5}(\mathrm{kta})(\mathrm{Hkta})\left(\mathrm{H}_{2} \mathrm{O}\right)\right]$ (1). There are 5 inequivalent $\mathrm{Na}$ sites within the structure, Na1 being 5-coordinate while $\mathrm{Na} 2, \mathrm{Na} 3, \mathrm{Na} 4$ and $\mathrm{Na} 5$ are 6-coordinate, all having rather irregular coordination geometry, with the water molecule bridging Na4 and Na5 (Figure 1). The

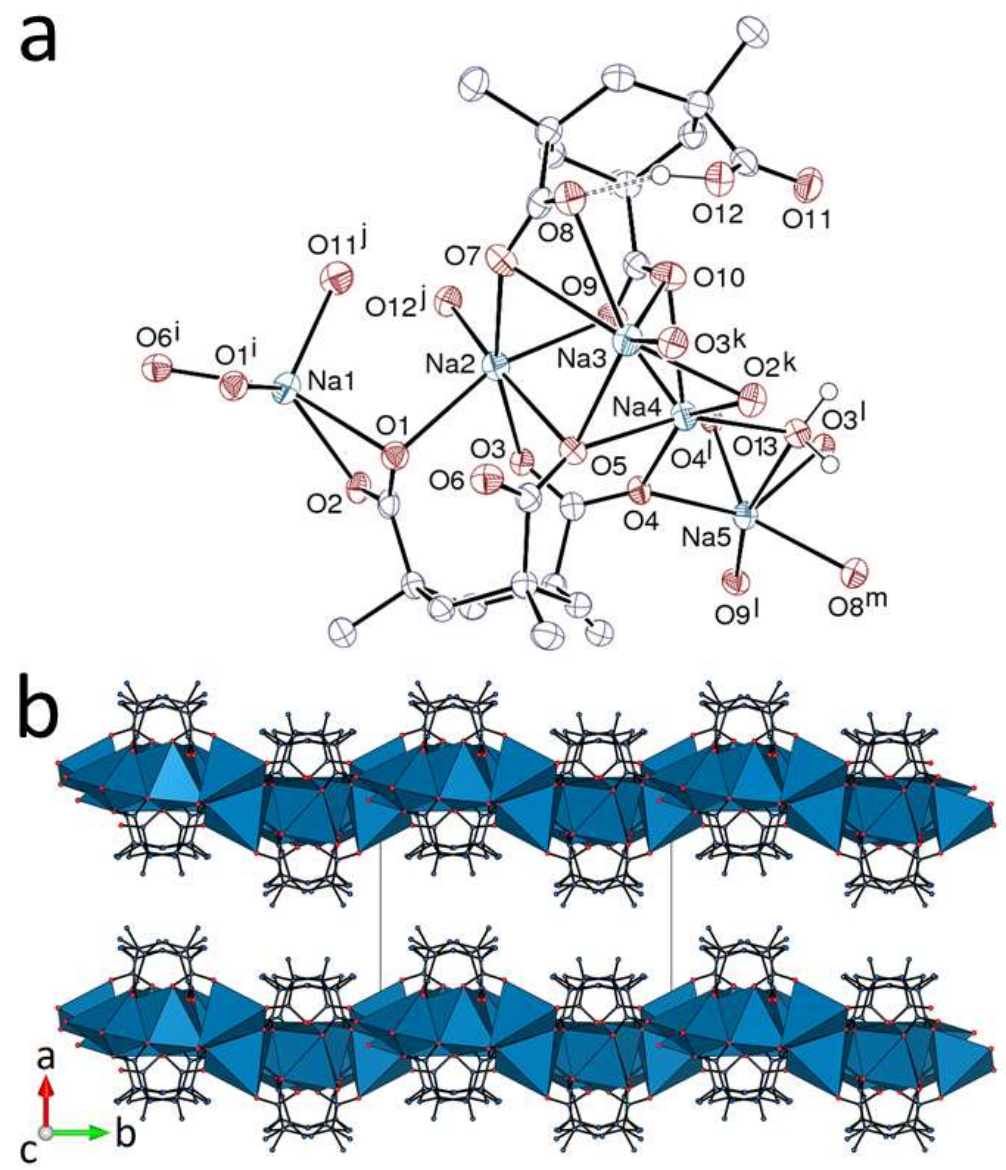

Figure 1. (a) View of complex 1. Displacement ellipsoids are drawn at the $50 \%$ probability level. Carbon-bound hydrogen atoms are omitted and the hydrogen bond is shown as a dashed line. Symmetry codes: $\mathrm{i}=-x, 2-y, 1$ $-z ; j=x, 3 / 2-y, z+1 / 2 ; k=x, 3 / 2-y, z-1 / 2 ; l=-x, 1-y, 1-z ; m=-x, y-1 / 2,1 / 2-z$. (b) Packing with layers viewed edge-on, showing sodium coordination polyhedra. 
trianion and dianion have separate identities and do not share the acidic proton, which in

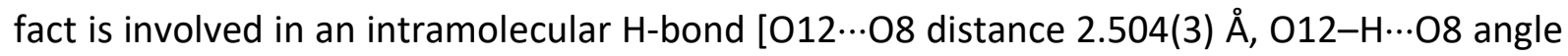
$162^{\circ}$ ]. All $5 \mathrm{Na}(\mathrm{I})$ cations are associated with the two anions in a diperiodic polymer lying in sheets parallel to (100). Both anions have a chair conformation with the carboxylate groups axial and oriented from both sides towards the interior of the sheet, so that the methylene and methyl groups form a lipophilic layer on each face of the sheet and thus may be involved in dispersion interactions with the similar layers of adjacent sheets. Part of the versatility of Kemp's triacid anions as ligands is seen in the different forms of coordination of each cation. Thus, Na1 is bound to one trianion through a 4-membered chelate ring, to a second through an 8-membered chelate ring, and to a dianion by coordination to the carbonyl-O of the carboxyl group which retains a proton. $\mathrm{Na} 2$ is bound to a trianion as a tridentate ligand (one oxygen from each carboxylate), to one dianion through an 8-membered chelate and to another dianion through a single carboxylate- $\mathrm{O}$. $\mathrm{Na} 3$ is bound to one dianion in a tridentate mode involving a 4-membered ring and an 8-membered ring formed by the two carboxylate groups, one trianion through an 8-membered chelate ring and one trianion through a single carboxylate-O. Na4 is bound to a dianion through a 4-membered chelate ring, a trianion through an 8-membered ring, another trianion through a single carboxylate- $\mathrm{O}$ and to a water molecule through which it is bridged to $\mathrm{Na} 5 . \mathrm{Na} 5$ is bound to two dianions and one trianion through single carboxylate-O atoms, one trianion through a 4-membered chelate as well as the water molecule. The $\mathrm{Na}-\mathrm{O}$ (carboxylato) bond lengths span the range of $2.257(2)-$ 2.744(2) $\AA$ and are thus unexceptional, the range for such bond lengths in the sodium carboxylate structures reported in the Cambridge Structural Database (CSD, version $5.40^{[27]}$ ) being $\sim 2.20-2.80 \AA$. While there are similarities to the known structure of 
$\left[\mathrm{Na}_{2}(\mathrm{Hkta})\left(\mathrm{H}_{2} \mathrm{O}\right)_{4}\right]^{[11]}$ in that there the ligands are again in chair form with carboxyl/ate groups axial and the coordination polymers lie in sheets with methyl and methylene groups lining the faces, there are also clear differences in that in $\left[\mathrm{Na}_{2}(\mathrm{Hkta})\left(\mathrm{H}_{2} \mathrm{O}\right)_{4}\right]$ the polymer units are monoperiodic strands parallel to the $b$ axis lying adjacent to one another to form the sheets, and each of the two inequivalent $\mathrm{Na}(\mathrm{I})$ ions is bound to just one $\mathrm{Hkta}^{2-}$ ligand through 8-membered chelate ring formation, with coordinated water occupying four other sites.

The structure of $\left[\mathrm{Sr}_{3}\left(\mathrm{H}_{3} \mathrm{kta}\right)(\mathrm{kta})_{2}\right]$ (2) shows close similarity to that of $\mathbf{1}$ in that the anions all have a chair conformation with the carboxyl/ate groups axial and a diperiodic polymer is present in which each face consists of lipophilic methyl and methylene groups (Figure 2). There are 3 inequivalent ligand units, all of them having threefold rotation symmetry. The remaining carboxylic proton has been found to be located on the sole uncoordinated oxygen atom, so that, due to symmetry, there is one $\mathrm{H}_{3} \mathrm{kta}$ and two $\mathrm{kta}^{3-}$ ligands. The Sr unit is unique, with a coordination form quite different to any of the Na units in 1 or $\left[\mathrm{Na}_{2}(\mathrm{Hkta})\left(\mathrm{H}_{2} \mathrm{O}\right)_{4}\right]$, being that of 8-coordination and involving five ligand units, one bound through a 4-membered chelate ring, two through an 8-membered, and two through single carboxylate-O atoms. The $\mathrm{Sr}-\mathrm{O}$ bond lengths span the range of $2.4541(16)-2.8734(15)$ $\AA$, to be compared with the range of $\sim 2.40-2.90 \AA$ from the CSD. Of the three inequivalent ligands, one $\left(\mathrm{kta}^{3-}\right)$ forms three 4-membered and three 8-membered chelate rings (each carboxylate group adopting the $\mu_{3}-\kappa^{2} O, O^{\prime}: \kappa^{1} O: \kappa^{1} O^{\prime}$ coordination mode), thus using all carboxylate-O atoms as donors and being bound to six cations, as does the other kta ${ }^{3-}$ ligand, in which the three carboxylate groups are bound in $\mu_{3}-\kappa^{1} O: \kappa^{1} O: \kappa^{1} O^{\prime}$ fashion, with formation of three 8-membered chelate rings, while the $\mathrm{H}_{3} \mathrm{kta}$ ligand forms just three 
a

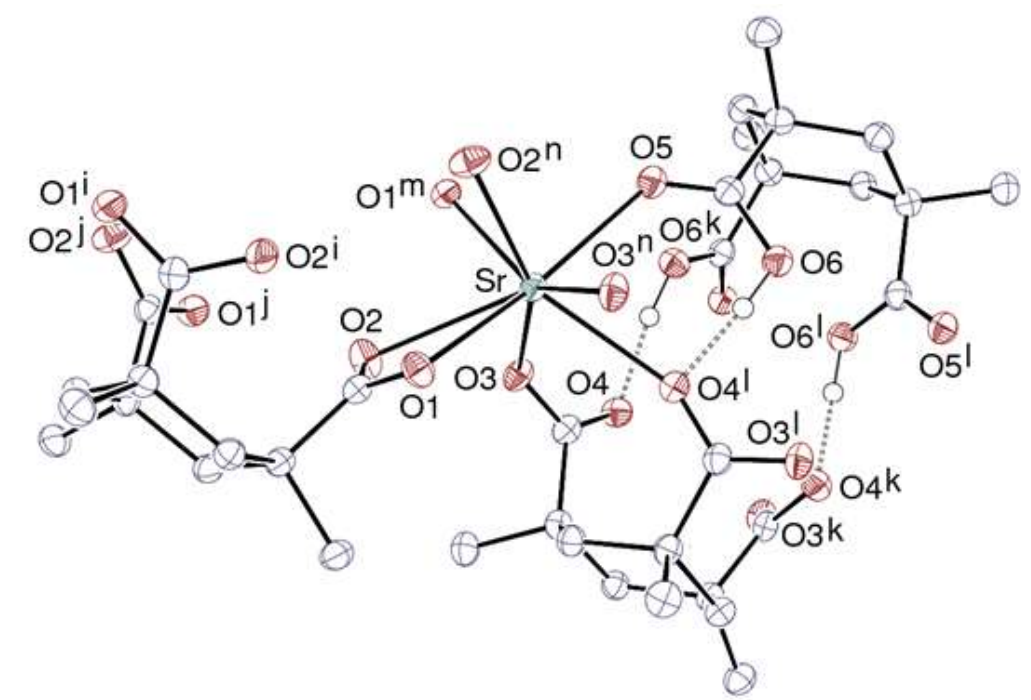

b
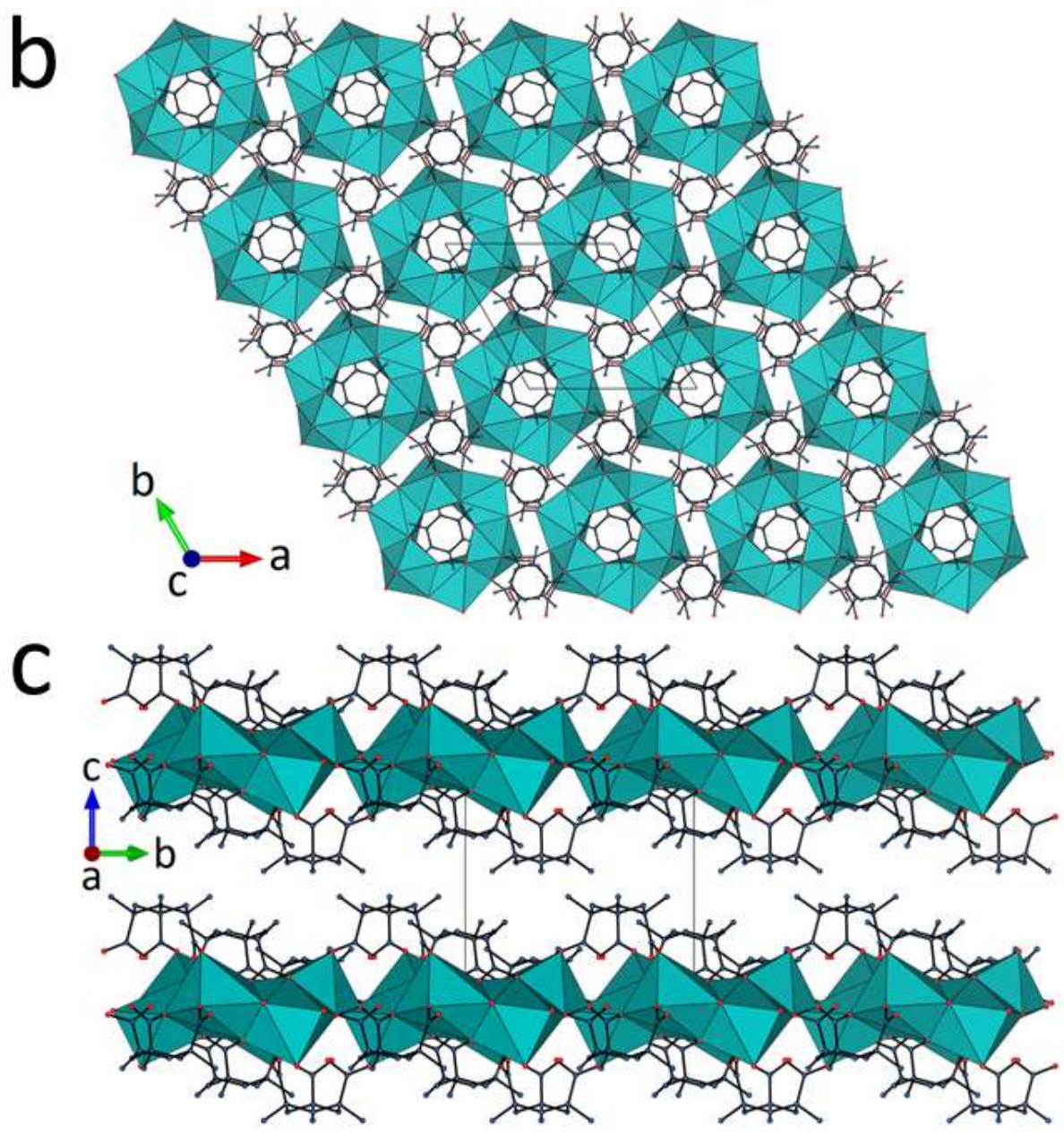

Figure 2. (a) View of complex 2. Displacement ellipsoids are drawn at the $50 \%$ probability level. Carbon-bound hydrogen atoms are omitted and hydrogen bonds are shown as dashed lines. Symmetry codes: $\mathrm{i}=-y, x-y, z ; \mathrm{j}$ $=y-x,-x, z ; k=1-y, x-y, z ; l=y-x+1,1-x, z ; m=y, y-x, 2-z ; n=x-y, x, 2-z$. (b) View of the diperiodic assembly showing strontium coordination polyhedra. (c) Packing with layers viewed edge-on. 
bonds involving one carboxylic-O of each group. Fusion of all these elements produces hexagonal rings of $\mathrm{Sr}$ atoms with triangular face-sharing coordination polyhedra (the latter of quite irregular geometry) centred around the tris- $\kappa^{2} O, O^{\prime}$-chelating ligands, these hexanuclear subunits being assembled into a diperiodic assembly parallel to (001). Observation of only the tripodal form with axial carboxyl groups of the anions in this and the $\mathrm{Na}$ (I) complexes could be seen as reinforcing the consideration of Kemp's triacid anions as preferably adopting this form and thus being particularly well suited to the formation of closed oligomers, as indeed observed with known $\mathrm{Fe}^{[12]}$ and $\mathrm{Mn}^{[13]}$ complexes and in some instances with uranyl derivatives. ${ }^{[14,15,18]}$ The present study of pure $\mathrm{Mn}(\mathrm{II})$ complexes show, however, that this is an oversimplification.

In the structure of $\left[\mathrm{Mn}_{3}(\mathrm{kta})_{2}\left(\mathrm{H}_{2} \mathrm{O}\right)_{3}\right](3)$, there are three inequivalent $\mathrm{Mn}(\mathrm{II})$ centres and two inequivalent ligand units, both of chair form with axial carboxylates (Figure 3). Of the $\mathrm{Mn}(\mathrm{II})$ centres, $\mathrm{Mn1}$ is 6-coordinate, being bound to one ligand via a 4-membered chelate ring and two others by a single carboxylate- $O$ each, with two water molecules completing the coordination sphere; $\mathrm{Mn} 2$ is 7-coordinate, being bound to two ligands via 8membered chelate rings and to a third via a 4-membered, with a single water molecule completing the coordination sphere; $\mathrm{Mn3}$ is 6-coordinate, with two ligands bound via 8membered chelate rings and a third by a 4-membered ring, and no coordinated water. The $\mathrm{Mn}-\mathrm{O}$ (carboxylato) bond lengths span the range of $2.0615(11)-2.4986(11) \AA$, to be compared with the range of $\sim 1.85-2.50 \AA$ from the CSD. The two ligands are bound to either four or five metal cations, and all carboxylate-O donors of both are coordinated. The coordinated water molecules are all involved in $\mathrm{H}$-bonding to carboxylate-O $[\mathrm{O} \cdots \mathrm{O}$ distances $2.6603(16)-3.1714(17) \AA, \mathrm{O}-\mathrm{H} \cdots \mathrm{O}$ angles $\left.125-170^{\circ}\right]$. The fusion of all these units produces a 
diperiodic polymer lying in sheets parallel to (100), once again with faces lined by the lipophilic methylene and methyl groups.

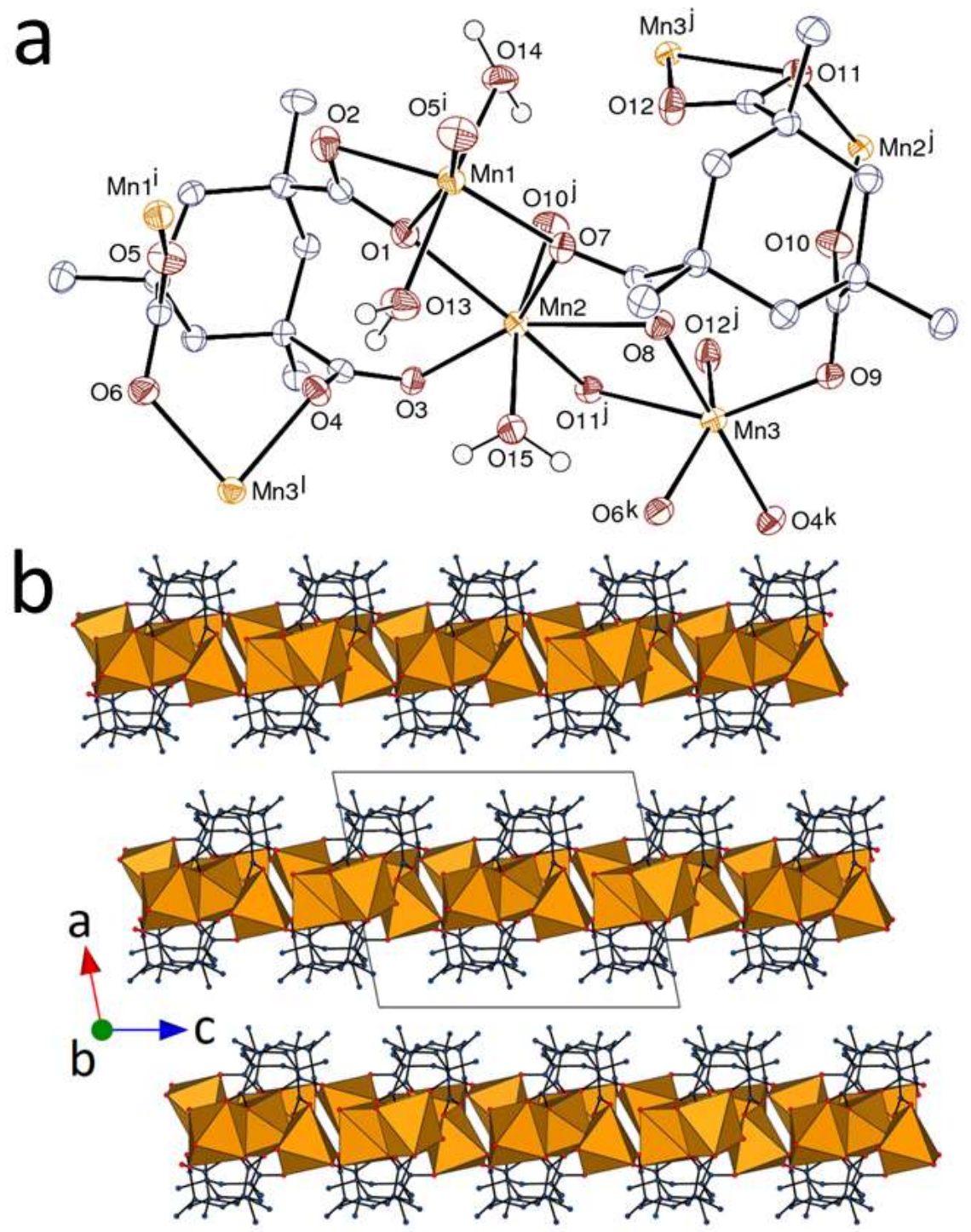

Figure 3. (a) View of complex 3. Displacement ellipsoids are drawn at the $50 \%$ probability level. Carbon-bound hydrogen atoms are omitted. Symmetry codes: $\mathrm{i}=1-x,-y,-z ; \mathrm{j}=1-x, 1-y,-z ; \mathrm{k}=1-x, y+1 / 2,1 / 2-z ; \mathrm{I}=1$ $-x, y-1 / 2,1 / 2-z$. (b) Packing with layers viewed edge-on, showing manganese coordination polyhedra.

The H-bonding interactions of the hexaquamanganese(II) ion play a particularly important role in defining the structure of the complex $\left[\mathrm{Mn}\left(\mathrm{H}_{2} \mathrm{O}\right)_{6}\right]\left[\mathrm{Mn} n_{5}(\mathrm{kta})_{4}\left(\mathrm{H}_{2} \mathrm{O}\right)_{4}\right](4)$, crystallized from the same solution as $\mathbf{3}$ and shown in Figure 4. As in all the structures 

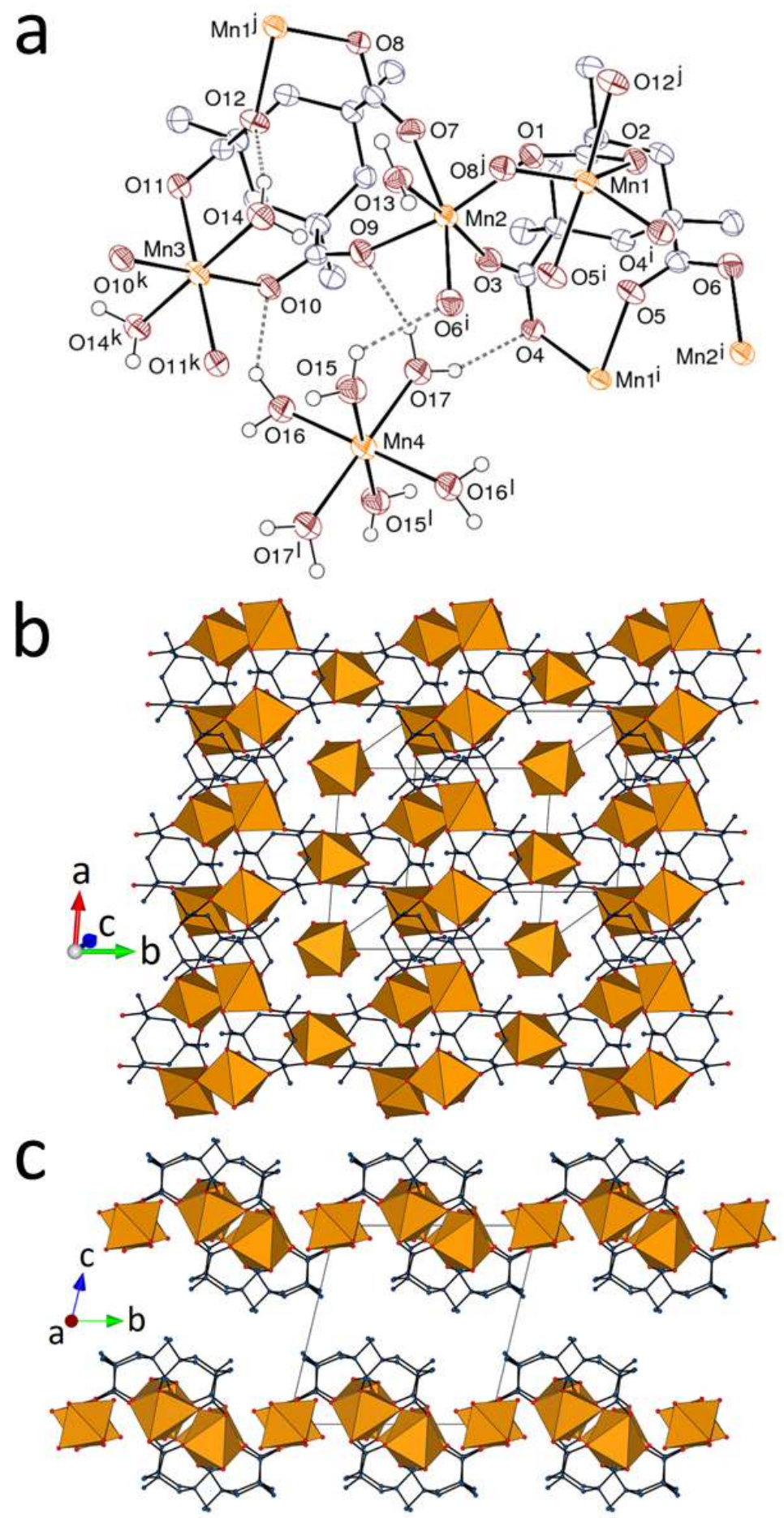

Figure 4. (a) View of complex 4. Displacement ellipsoids are drawn at the $30 \%$ probability level. Carbon-bound hydrogen atoms are omitted and hydrogen bonds are shown as dashed lines. Symmetry codes: $\mathrm{i}=-x, 1-y, 2-$ $z ; j=1-x, 1-y, 2-z ; k=1-x, 2-y, 2-z ; 1=-x, 2-y, 2-z$. (b) View of the diperiodic assembly showing manganese coordination polyhedra. (c) Packing with layers viewed edge-on. 
described to this point, however, all the metal ion species can be considered to lie in sheets, here parallel to (001), and the two inequivalent ligand units have chair conformations with the carboxylate groups axial. The $\left[\mathrm{Mn}_{5}(\mathrm{kta})_{4}\left(\mathrm{H}_{2} \mathrm{O}\right)_{4}\right]^{2-}$ component is a diperiodic polymer forming thick, undulating layers, with methyl and methylene units projecting from both faces, and defining cavities large enough to accommodate the centrosymmetric $\left[\mathrm{Mn}\left(\mathrm{H}_{2} \mathrm{O}\right)_{6}\right]^{2+}$ ions. There are three inequivalent $\mathrm{Mn}$ centres in the diperiodic polymer, $\mathrm{Mn} 1$ being 6coordinate through 8-membered ring chelation by two inequivalent ligands and 4membered ring chelation by a third, $\mathrm{Mn} 2$ being 6 -coordinate through 8 -membered ring chelation by two inequivalent ligands, a single carboxylate-O of a third ligand and a water molecule, and $\mathrm{Mn3}$ (located on an inversion centre) being 6-coordinate through 8membered ring chelation by two equivalent ligands and the binding of two trans-disposed water molecules. The $\mathrm{Mn}-\mathrm{O}$ (carboxylato) bond lengths are in the range of $2.077(2)-2.450(3)$ Å. H-bond donation to carboxylate-O involves all the coordinated water molecules [O… distances $2.707(4)-3.189(3) \AA$, $\mathrm{O}-\mathrm{H} \cdots \mathrm{O}$ angles $113-167^{\circ}$, fixing in particular the $\left[\mathrm{Mn}\left(\mathrm{H}_{2} \mathrm{O}\right)_{6}\right]^{2+}$ ions within the polymer cavities, so that the form of the polymer is clearly adapted to this factor (Figure $4 b$ ).

The effect of removing any $\mathrm{H}$-bond donor is dramatically evident in the structure of $\left[\mathrm{Mn}_{6}(\mathrm{kta})_{4}(\mathrm{nmp})_{3}\right](5)$, where $\mathrm{nmp}$ is $N$-methyl-2-pyrrolidone, which crystallizes in the polar space group $R 3 C$ (Figure 5). Although there is again a diperiodic polymer present incorporating both inequivalent $\mathrm{Mn}(\mathrm{II})$ ions, there are four inequivalent ligand units, all with threefold rotation symmetry, two of which adopt a chair form with triaxial carboxylates while the other two adopt a chair form with triequatorial carboxylates. $\mathrm{Mn} 1$ is bound in an 8-membered chelate ring to one triaxial ligand as well as to one other triaxial and two 


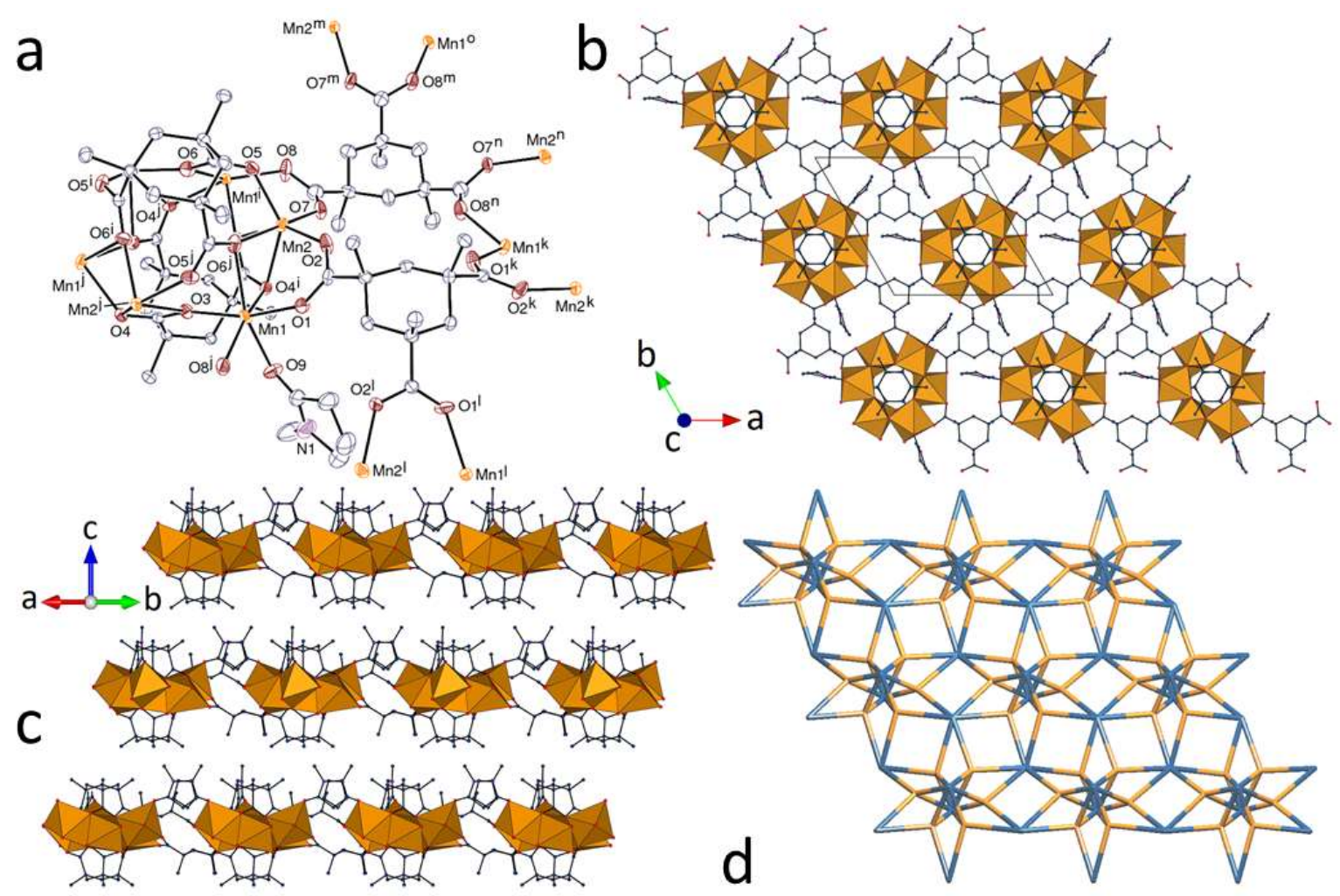

Figure 5. (a) View of complex 5. Displacement ellipsoids are drawn at the $30 \%$ probability level and hydrogen atoms are omitted. Symmetry codes: $\mathrm{i}=y-x+1,1-x, z ; \mathrm{j}=1-y, x-y, z ; \mathrm{k}=1-y, x-y+1, z ; \mathrm{I}=y-x, 1-x, z$; $\mathrm{m}=2-y, x-y+1, z ; n=y-x+1,2-x, z ; 0=x+1, y+1, z$. (b) View of the diperiodic assembly showing manganese coordination polyhedra. (c) Packing with layers viewed edge-on. (d) Nodal representation of the network (orange, manganese; blue, tricarboxylate ligand). Orientation slightly rotated with respect to that in (b).

triequatorial ligands by a single carboxylate-O on each, and to one $\mathrm{nmp}-\mathrm{O}$, thus being 6coordinate, with a distorted octahedral environment. Mn2 is also 6-coordinate, with the same ligand environment as $\mathrm{Mn} 1$ except that it lacks the $\mathrm{nmp}-\mathrm{O}$ and one of the triaxial ligands is 4-membered chelating. The $\mathrm{Mn}-\mathrm{O}$ (carboxylato) bond lengths span the usual range of $2.062(4)-2.421(3) \AA$. The combination of these interactions means that the $\mathrm{Mn}(\mathrm{II})$ ions in nearly planar, threefold rotation-symmetric $(\mathrm{Mn} 1)_{3}(\mathrm{Mn} 2)_{3}$ units, with the manganese coordination polyhedra sharing alternately one edge or one vertex, are bridged by two 
triaxial ligands, one to each side of the mean plane and linked to other such units by bridging of triequatorial ligands, each carboxylate of the latter ligand being involved in $\mu_{2}-\kappa^{1} O, \kappa^{1} O^{\prime}$ bridging of $\mathrm{Mn} 1$ and $\mathrm{Mn} 2$ centres in the same $(\mathrm{Mn} 1)_{3}(\mathrm{Mn} 2)_{3}$ unit. Both metal ions are fourconnected nodes and all ligands are six-coordinated nodes in the diperiodic assembly formed parallel to (001). Despite some differences in symmetry, the structure of this $\mathrm{Mn}(\mathrm{II})$ complex is akin to that of complex 3 , and virtually identical with that of $\left[\mathrm{Pb}_{3}(\mathrm{kta})_{2}(\mathrm{dmf})_{3}\right]$ ( $\mathrm{dmf}=\mathrm{N}, \mathrm{N}$-dimethylformamide), although the coordination number of $\mathrm{Pb}(\mathrm{II})$ is $8{ }^{[17]}$ Thus, adoption of a chair form with carboxylate groups disposed equatorially is not necessarily a feature restricted to very heavy metal complexes of Kemp's triacid, although with $\mathrm{Mn}(\mathrm{II})$ as with $\mathrm{Pb}(\mathrm{II})^{[17]}$ and $\mathrm{U}(\mathrm{VI}),{ }^{[14,15]}$ it is associated with the formation of sheet-like coordination polymers. An obvious implication of the present results, one supported by numerous other observations, is that $\mathrm{H}$-bonding can have a major influence upon the structures of polycarboxylate coordination polymers. This is not to say, however, that the nature of the metal ion is unimportant, an assertion supported by what is seen in the structure of $\left[\mathrm{UO}_{2} \mathrm{Cs}(\mathrm{kta})\right]$

The structure of $\left[\mathrm{UO}_{2} \mathrm{Cs}(\mathrm{kta})\right]$ (6) provides a further example of a diperiodic coordination polymer. This complex is isomorphous to the previously reported $\left[\mathrm{H}_{2} \mathrm{NMe}_{2}\right]\left[\mathrm{UO}_{2}(\mathrm{kta})\right] \cdot{ }^{[16]}$ As is common with uranyl carboxylate complexes with a $1: 3$ $\mathrm{U} /$ carboxylate ratio, the $\mathrm{U}(\mathrm{VI})$ centre, located on a mirror plane, has a hexagonal bipyramidal form involving three $\kappa^{2} O, O^{\prime} 4$-membered chelate rings, each here from a different trianionic ligand unit (Figure 6). The U-O(oxido) bond lengths are $1.770(8)$ and $1.795(7) \AA$, and the $U-$ O(carboxylato) bond lengths span the usual range of $2.444(5)-2.485(6) \AA$. The caesium ions, which are disordered over two sites, one located on a symmetry plane and the other slightly 


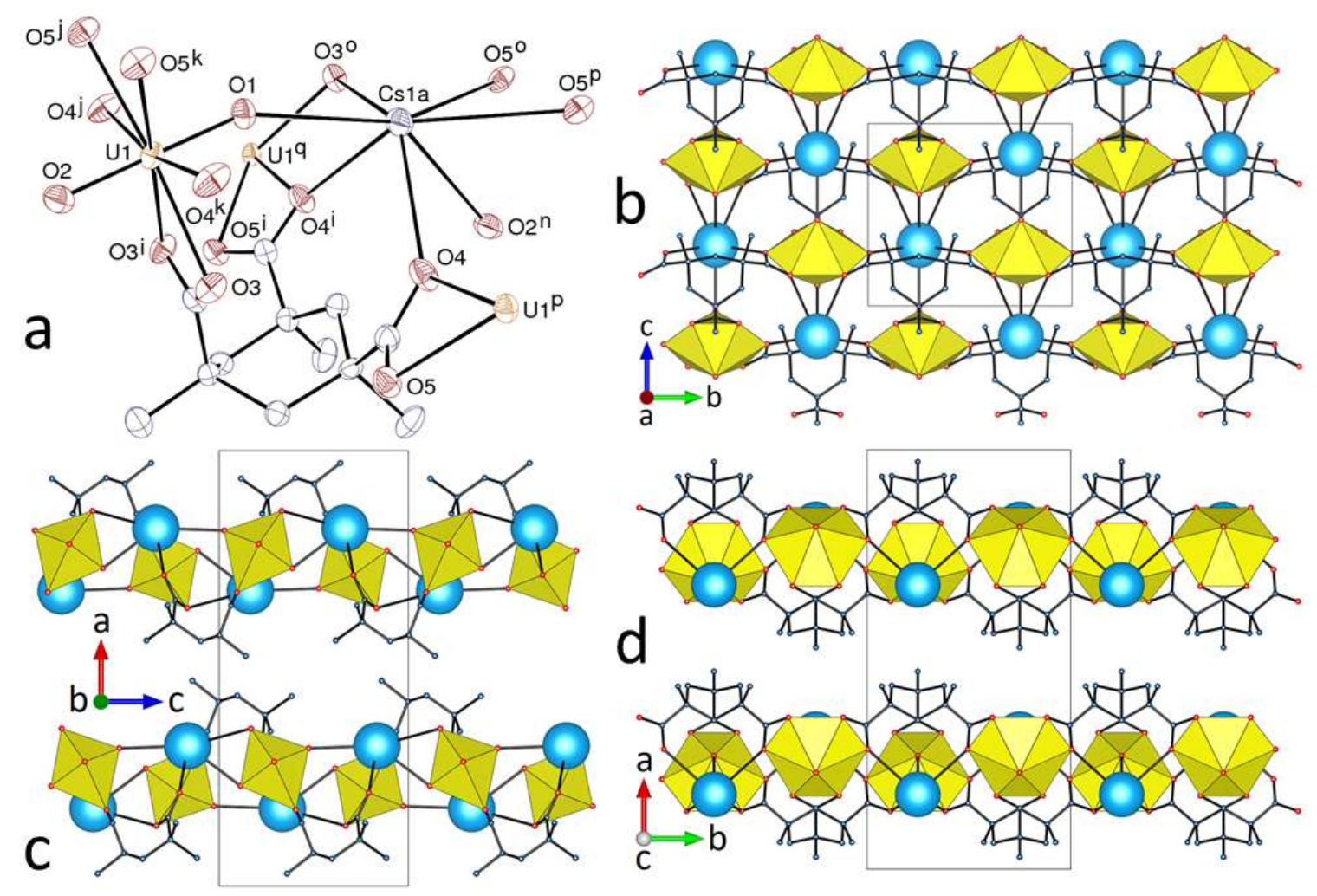

Figure 6. (a) View of complex 6. Displacement ellipsoids are drawn at the $40 \%$ probability level and hydrogen atoms are omitted. Symmetry codes: $\mathrm{i}=x, 1 / 2-y, z ; \mathrm{j}=1 / 2-x, y+1 / 2, z-1 / 2 ; \mathrm{k}=1 / 2-x,-y, z-1 / 2 ; \mathrm{I}=x, y, z$ $-1 ; \mathrm{m}=x, 1 / 2-y, z-1 ; \mathrm{n}=x, y, z+1 ; 0=1 / 2-x, y+1 / 2, z+1 / 2 ; \mathrm{p}=1 / 2-x,-y, z+1 / 2 ; \mathrm{q}=1 / 2-x, 1-y, z+$ 1/2. (b) View of the diperiodic assembly with uranium coordination polyhedra yellow and caesium cations shown as blue spheres. (c) and (d) Two views of the packing with layers edge-on. Only one position of the disordered caesium atom is shown in all views.

displaced from the plane, in general position, are bound to four carboxylate oxygen atoms, with Cs-O bond lengths in the range of 2.946(7)-3.496(6) $\AA$, in agreement with the range of 2.8-3.7 $\AA$ in the structures reported in the CSD. They are also bound to two oxo groups from two uranyl cations, with Cs-O bond lengths of 3.045(9)-3.289(7) $\AA$, at the lower end of the range usually found for such bonds, 2.96-3.89 $\AA .{ }^{[28]}$ What is unusual in this of the present structures is that the unique ligand, which has mirror symmetry, adopts a regular boat conformation with two carboxylate groups equatorial and one axial, leading to their 
orientation in two near-orthogonal directions, a form for which the term "dipodal" seems appropriate. This conformation is very rarely observed in Kemp's triacid anions, since, apart from these two isomorphous uranyl complexes, deviation from the chair conformation is only found in two cases of organic compounds including $\mathrm{kta}^{3-}$ which display conformations described as twisted or twisted boat. ${ }^{[29,30]}$ In the present case, this conformation appears well suited to the complexation of two metal cations, the uranyl ion being chelated by the carboxylate group in axial position, and the caesium atom being chelated by the two carboxylate groups in equatorial position, with formation of an 8-membered chelate ring, the bridging uranyl oxido group making a link between the two cations. When considered alone, uranyl cations and ligands in 6 are both three-coordinated nodes and the diperiodic network they form, parallel to (100), has the point symbol $\left\{6^{3}\right\}$ and the hcb topological type, as in $\left[\mathrm{H}_{2} \mathrm{NMe}_{2}\right]\left[\mathrm{UO}_{2}(\mathrm{kta})\right]$. The caesium cations appear to have a decorative role in that they are not an essential part of the polymer but, given evidence that they may have a unique form of interaction with carboxylates, ${ }^{4}$ they have possibly an influence favouring the adoption of the boat conformation. This influence is perhaps to be contrasted with that of protonated 2,2'-bipyridine in $\left[\right.$ bipyH] $\left[\mathrm{UO}_{2}(\mathrm{kta})\right]^{,[15]}$ where the anions have a chair conformation with equatorial carboxylates, the diperiodic coordination polymer having also the hcb topology, but the fact that 6 is similar to $\left[\mathrm{H}_{2} \mathrm{NMe}_{2}\right]\left[\mathrm{UO}_{2}(\mathrm{kta})\right]$ indicates that whatever factors are operative, they must be rather subtle.

\section{Conclusions}

We have reported the synthesis and crystal structure of six complexes of Kemp's triacid or its anions with metal cations spanning a large range of size and preferred environment. Although the tripodal chair conformation of the ligand with the three carboxyl/ate groups 
axial is most common, the discoidal chair conformation with the three groups equatorial is found here in one $\mathrm{Mn}(\mathrm{II})$ complex, and the boat conformation with one axial and two equatorial groups, designated dipodal, is observed for the second time in a uranyl ion complex. While ligand flexibilty is recognised as a cause of a loss in selectivity in metal ion binding in solution, ${ }^{[31]}$ it can be advantageous in the construction of crystalline coordination polymers, ${ }^{[32]}$ both because it renders possible the generation of structures unique to a given metal ion ${ }^{[33]}$ and because it may lead to useful properties of these materials such as "breathing" of the crystals. ${ }^{[34]}$ Kemp's triacid is a molecule of limited flexibility due to its cyclic nature but the present structures further demonstrate that it is capable of forming coordination complexes in at least three different conformations. While chair conformers with triaxial and triequatorial dispositions of the carboxyl/ate groups may be found in complexes of metal ions across a wide range of the Periodic Table, the boat form of the ligand may well be limited to uranyl ion complexes, indicating that Kemp's triacid has both ubiquity and specificity in its solid state coordination chemistry. The importance of $\mathrm{H}$ bonding noted in the present structures is an aspect in common with a huge range of coordination polymers but does seem to have nearly unique features in Kemp's triacid derivatives in the ways in which the charge on a metal ion is neutralised by a mixture of different protonated forms of the ligand. Such is not a prominent feature of the structures of the threefold-symmetric, tripodal ligand 1,3,5-benzenetriacetate, for example. ${ }^{[35]}$ Another peculiarity of complexes with Kemp's triacid anions, previously noted in cases displaying various periodicities ${ }^{[14-16]}$ and apparent also in all the present diperiodic complexes, whatever the ligand conformation, is the segregation of the hydrophobic parts on the outside of the polymeric assemblies, sometimes as bulging groups, this being probably a major influence on the geometry of the species formed. 


\section{Experimental Section}

General: Kemp's triacid $\left(\mathrm{H}_{3} \mathrm{kta}\right)$ and $\mathrm{Mn}\left(\mathrm{NO}_{3}\right)_{2} \cdot 4 \mathrm{H}_{2} \mathrm{O}$ were from Sigma-Aldrich, and $\mathrm{UO}_{2}\left(\mathrm{NO}_{3}\right)_{2} \cdot 6 \mathrm{H}_{2} \mathrm{O}$ (depleted uranium, R. P. Normapur, 99\%) was from Prolabo. For all syntheses under solvo-hydrothermal conditions (complexes 2-6), the mixtures in demineralized water were placed in $10 \mathrm{~mL}$ tightly closed glass vessels and heated at $140{ }^{\circ} \mathrm{C}$ under autogenous pressure. In all cases, the reactions produced only a small homogeneous crop of single crystals, suitable for crystal structure determination, but insufficient for further characterization.

Caution! Uranium is a radioactive and chemically toxic element, and uranium-containing samples must be handled with suitable care and protection.

[Na $\left.\mathbf{N}_{\mathbf{H}}(\mathrm{kta})(\mathbf{H k t a})\left(\mathrm{H}_{2} \mathrm{O}\right)\right]$ (1): Recrystallisation by vapour diffusion of ethanol into its aqueous solution of the amorphous precipitate, assumed to be $\mathrm{Na}_{3} \mathrm{kta}$, obtained by the addition of ethanol to a solution of $\mathrm{H}_{3} \mathrm{kta}$ in an excess of aqueous $\mathrm{Na}_{2} \mathrm{CO}_{3}$, provided crystalline material for which the composition was deduced from the structure determination.

[Sr $\left.3\left(\mathrm{H}_{3} \mathrm{kta}\right)(\mathbf{k t a})_{2}\right]$ (2): Kemp's triacid $(13 \mathrm{mg}, 0.05 \mathrm{mmol})$ and $\mathrm{Sr}\left(\mathrm{NO}_{3}\right)_{2}(43 \mathrm{mg}, 0.20 \mathrm{mmol})$ were dissolved in a mixture of water $(0.9 \mathrm{~mL})$ and $\mathrm{nmp}(0.7 \mathrm{~mL})$, giving colourless crystals of complex $\mathbf{2}$ in low yield within one week. 
$\left[\mathrm{Mn}_{3}(\mathrm{kta})_{2}\left(\mathrm{H}_{2} \mathrm{O}\right)_{3}\right](3)$ and $\left[\mathrm{Mn}\left(\mathrm{H}_{2} \mathrm{O}\right)_{6}\right]\left[\mathrm{Mn}_{5}(\mathbf{k t a})_{4}\left(\mathrm{H}_{2} \mathrm{O}\right)_{4}\right]$ (4): Kemp's triacid (13 mg, 0.05 $\mathrm{mmol}), \mathrm{Mn}\left(\mathrm{NO}_{3}\right)_{2} \cdot 4 \mathrm{H}_{2} \mathrm{O}(25 \mathrm{mg}, 0.10 \mathrm{mmol})$, and $\mathrm{DABCO}(11 \mathrm{mg}, 0.10 \mathrm{mmol}$ ) were dissolved in a mixture of water $(0.9 \mathrm{~mL})$ and $\mathrm{nmp}(0.4 \mathrm{~mL})$, giving a mixture of colourless crystals of complexes $\mathbf{3}$ and $\mathbf{4}$ in low yield within one week.

$\left[\mathrm{Mn}_{6}(\mathbf{k t a})_{4}(\mathrm{nmp})_{3}\right]$ (5): Kemp's triacid $(13 \mathrm{mg}, 0.05 \mathrm{mmol})$ and $\mathrm{Mn}\left(\mathrm{NO}_{3}\right)_{2} \cdot 4 \mathrm{H}_{2} \mathrm{O}(25 \mathrm{mg}, 0.10$ $\mathrm{mmol})$ were dissolved in a mixture of water $(0.9 \mathrm{~mL})$ and NMP $(0.4 \mathrm{~mL})$. After heating for two months, the solution was left to slowly evaporate, giving colourless crystals of complex 5 in low yield over a two months' period.

[UO $\left.{ }_{2} \mathrm{Cs}(\mathrm{kta})\right]$ (6): Kemp's triacid (13 mg, $\left.0.05 \mathrm{mmol}\right), \mathrm{UO}_{2}\left(\mathrm{NO}_{3}\right)_{2} \cdot 6 \mathrm{H}_{2} \mathrm{O}(25 \mathrm{mg}, 0.05 \mathrm{mmol})$, and $\mathrm{CsNO}_{3}(39 \mathrm{mg}, 0.20 \mathrm{mmol})$ were dissolved in a mixture of water $(0.9 \mathrm{~mL})$ and NMP $(0.4$ $\mathrm{mL}$ ), giving yellow crystals of complex 6 in low yield within two weeks.

Crystallography: The data were collected at 150(2) K on a Nonius Kappa-CCD area detector

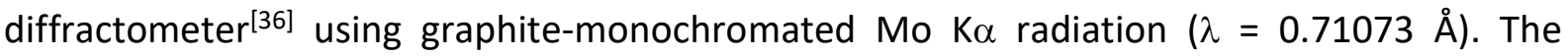
crystals were introduced into glass capillaries with a protective coating of Paratone- $\mathrm{N}$ oil (Hampton Research). The unit cell parameters were determined from ten frames, then refined on all data. The data (combinations of $\varphi$ - and $\omega$-scans with a minimum redundancy of 4 for $90 \%$ of the reflections) were processed with HKL2000. ${ }^{[37]}$ Absorption effects were corrected for empirically with the program SCALEPACK. ${ }^{[37]}$ The structures were solved by direct methods with SHELXS ${ }^{[38]}$ or by intrinsic phasing with SHELXT, ${ }^{[39]}$ expanded by subsequent difference Fourier synthesis and refined by full-matrix least-squares on $F^{2}$ with SHELXL. ${ }^{[40]}$ All non-hydrogen atoms were refined with anisotropic displacement parameters. 
When present, the hydrogen atoms bound to oxygen atoms were found on difference Fourier maps, and the carbon-bound hydrogen atoms were introduced at calculated positions; all hydrogen atoms were treated as riding atoms with an isotropic displacement parameter equal to 1.2 times that of the parent atom (1.5 for $\mathrm{CH}_{3}$, with optimized geometry). Some voids in the structure of $\mathbf{5}$ probably indicate the presence of unresolved solvent molecules; this structure was refined as a 2-component inversion twin, with a Flack parameter of $0.44(4)$. In complex 6 , the caesium atom is disordered over two sites which were refined with occupancies of 0.5 (Cs1A, located on a mirror plane), or 0.25 (Cs1B, in general position). Crystal data and structure refinement parameters are given in Table 1 . The molecular plots were drawn with ORTEP-3 ${ }^{[41]}$ and the polyhedral representations with VESTA. ${ }^{[42]}$ Topological analyses were conducted with ToposPro. ${ }^{[43]}$

Table 1. Crystal data and structure refinement details.

\begin{tabular}{|c|c|c|c|c|c|c|}
\hline & 1 & 2 & 3 & 4 & 5 & 6 \\
\hline Empirical formula & $\mathrm{C}_{24} \mathrm{H}_{33} \mathrm{Na}_{5} \mathrm{O}_{13}$ & $\mathrm{C}_{12} \mathrm{H}_{16} \mathrm{O}_{6} \mathrm{Sr}$ & $\mathrm{C}_{24} \mathrm{H}_{36} \mathrm{Mn}_{3} \mathrm{O}_{15}$ & $\mathrm{C}_{48} \mathrm{H}_{80} \mathrm{Mn}_{6} \mathrm{O}_{34}$ & $\mathrm{C}_{63} \mathrm{H}_{87} \mathrm{Mn}_{6} \mathrm{~N}_{3} \mathrm{O}_{27}$ & $\mathrm{C}_{12} \mathrm{H}_{15} \mathrm{CsO}_{8} \mathrm{U}$ \\
\hline$M\left(\mathrm{~g} \mathrm{~mol}^{-1}\right)$ & 644.45 & 343.87 & 729.35 & 1530.76 & 1647.99 & 658.18 \\
\hline Crystal system & monoclinic & trigonal & monoclinic & triclinic & trigonal & orthorhombic \\
\hline Space group & $P 2_{1} / c$ & $P-3$ & $P 2_{1} / c$ & $P_{\overline{\mathrm{I}}}$ & $R 3 c$ & Pnma \\
\hline$a(\AA)$ & $14.2793(10)$ & $13.1497(2)$ & $12.4763(5)$ & $10.4421(5)$ & $14.0042(3)$ & $20.0155(17)$ \\
\hline$b(\AA)$ & $15.2955(11)$ & $13.1497(2)$ & $14.5900(4)$ & $12.2118(7)$ & $14.0042(3)$ & $9.7071(4)$ \\
\hline$c(\AA)$ & $14.2147(7)$ & $12.4529(3)$ & $15.6202(5)$ & $12.8752(8)$ & $67.091(2)$ & $8.6825(7)$ \\
\hline$\alpha\left({ }^{\circ}\right)$ & 90 & 90 & 90 & $75.926(3)$ & 90 & 90 \\
\hline$\beta\left({ }^{\circ}\right)$ & $115.594(4)$ & 90 & $101.177(2)$ & $72.647(3)$ & 90 & 90 \\
\hline$\gamma\left(\left(^{\circ}\right)\right.$ & 90 & 120 & 90 & $85.764(4)$ & 120 & 90 \\
\hline$V\left(\AA^{3}\right)$ & $2800.0(3)$ & $1864.80(7)$ & $2789.40(16)$ & $1520.04(15)$ & $11394.9(6)$ & $1686.9(2)$ \\
\hline$z$ & 4 & 6 & 4 & 1 & 6 & 4 \\
\hline Reflections collected & 58979 & 35669 & 104565 & 74356 & 94782 & 46591 \\
\hline Independent reflections & 5330 & 3794 & 8502 & 5763 & 4807 & 1693 \\
\hline Observed reflections $[I>2 \sigma(I)]$ & 3531 & 3380 & 6585 & 4599 & 4490 & 1452 \\
\hline$R_{\text {int }}$ & 0.068 & 0.021 & 0.034 & 0.092 & 0.020 & 0.024 \\
\hline Parameters refined & 385 & 175 & 385 & 406 & 304 & 123 \\
\hline$R_{1}$ & 0.054 & 0.029 & 0.032 & 0.051 & 0.049 & 0.035 \\
\hline $\mathrm{w} R_{2}$ & 0.104 & 0.081 & 0.083 & 0.143 & 0.138 & 0.095 \\
\hline$S$ & 1.056 & 1.141 & 1.026 & 1.037 & 1.043 & 1.120 \\
\hline$\Delta \rho_{\min }\left(\mathrm{e} \AA^{-3}\right)$ & -0.24 & -0.65 & -0.51 & -0.75 & -0.36 & -1.17 \\
\hline$\Delta \rho_{\max }\left(\mathrm{e} \AA^{-3}\right)$ & 0.25 & 0.51 & 0.43 & 0.88 & 0.97 & 2.32 \\
\hline
\end{tabular}


CCDC 1965436 (for 1), 1965437 (for 2), 1965438 (for 3), 1965439 (for 4), 1965440 (for 5), and 1965441 (for 6) contain the supplementary crystallographic data for this paper. These data can be obtained free of charge from The Cambridge Crystallographic Data Centre via www.ccdc.cam.ac.uk/data request/cif.

\section{References}

[1] B. J. Hathaway, in: G. Wilkinson, R. D. Gillard, J. A. McCleverty (Eds.), Comprehensive Coordination Chemistry I, vol. 5, Pergamon Press, Oxford, 1987, pp. 533-774 (Chapter 53).

[2] M. N. Hu, A. Morsali, L. Aboutorabi, Coord. Chem. Rev. 2011, 255, 2821-2859.

[3] T. Loiseau, I. Mihalcea, N. Henry, C. Volkringer, Coord. Chem. Rev. 2014, 266-267, 69109.

[4] J. Harrowfield, P. Thuéry, Aust. J. Chem. 2016, 69, 505-511.

[5] M. C. Hong, L. Chen, Design and Construction of Coordination Polymers, WileyInterscience, Hoboken, NJ, 2009.

[6] L. R. MacGillivray, Metal-Organic Frameworks: Design and Application, WileyInterscience: Hoboken, NJ, 2010.

[7] S. T. Meek, J. A. Greathouse, M. D. Allendorf, Adv. Mater. 2011, 23, 249-267.

[8] J. R. Li, J. Sculley, H. C. Zhou, Chem. Rev. 2012, 112, 869-932.

[9] M. B. Andrews, C. L. Cahill, Chem. Rev. 2013, 113, 1121-1136.

[10] S. Kaskel, The Chemistry of Metal-organic Frameworks, John Wiley and Sons, NY, 2016, pp. 493-522.

[11] A. Bencini, A. Bianchi, M. I. Burguete, P. Dapporto, A. Doménech, E. García-España, S. V. Luis, P. Paoli, J. A. Ramírez, J. Chem. Soc., Perkin Trans 2 1994, 569-577. 
[12] Y. Takemura, Y. Okui, B. Kure, T. Nakajima, T. Tanase, M. Mikuriya, M. Takahashi, Inorg. Chim. Acta 2011, 379, 100-108.

[13] Y. Okui, F. A. Catusanu, R. Kubota, B. Kure, T. Nakajima, T. Tanase, T. Kajiwara, M. Mikuriya, H. Miyasaka, M. Yamashita, Eur. J. Inorg. Chem. 2011, 4325-4330.

[14] P. Thuéry, Cryst. Growth Des. 2014, 14, 901-904.

[15] P. Thuéry, Cryst. Growth Des. 2014, 14, 2665-2676.

[16] P. Thuéry, J. Harrowfield, Polyhedron. 2015, 98, 5-11.

[17] S. B. Kim, D. W. Lee, S. K. Chang, K. M. Ok, Chem. Commun. 2015, 51, 1316613169.

[18] P. Thuéry, J. Harrowfield, Dalton Trans 2017, 46, 13660-13667.

[19] S. Herold, S. J. Lippard, J. Am. Chem. Soc. 1997, 119, 145-156.

[20] S. P. Watton, P. Fuhrmann, L. E. Pence, A. Caneschi, A. Cornia, G. L. Abati, S. J. Lippard, Angew. Chem. Int. Ed. Engl. 1997, 36, 2774-2776.

[21] C. He, S. J. Lippard, J. Am. Chem. Soc. 1998, 120, 105-113.

[22] D. P. Steinhuesel, S. J. Lippard, Inorg. Chim. Acta 1998, 270, 527-536.

[23] D. D. LeCloux, R. Davydov, S. J. Lippard, J. Am. Chem. Soc. 1998, 120, 6810-6811.

[24] D. D. LeCloux, R. Davydov, S. J. Lippard, Inorg. Chem. 1998, 37, 6814-6826.

[25] M. Kato, T. Tanase, M. Mikuriya, Inorg. Chem. 2006, 45, 2925-2941.

[26] D. S. Kemp, K. S. Petrakis, J. Org. Chem. 1981, 46, 5140-5143.

[27] a) C. R. Groom, I. J. Bruno, M. P. Lightfoot, S. C. Ward, Acta Crystallogr., Sect. B 2016, 72, 171-179; b) R. Taylor, P. A. Wood, Chem. Rev. 2019, 119, 9427-9477.

[28] See, for example: a) P. Thuéry, B. Masci, Dalton Trans. 2003, 2411-2417; b) P. A. Giesting, N. J. Porter, P. C. Burns, Z. Kristallogr. 2006, 221, 589-599; c) B. Masci, P. Thuéry, CrystEngComm 2008, 1082-1087; d) P. O. Adelani, T. E. Albrecht-Schmitt, 
Angew. Chem. Int. Ed. 2010, 49, 8909-8911; e) P. O. Adelani, A. G. Oliver, T. E. Albrecht-Schmitt, Cryst. Growth Des. 2011, 11, 3072-3080; f) P. O. Adelani, T. E. Albrecht-Schmitt, Inorg. Chem. 2011, 50, 12184-12191; g) A. V. Vologzhanina, A. V. Savchenkov, A. O. Dmitrienko, A. A. Korlyukov, I. S. Bushmarinov, D. V. Pushkin, L. B. Serezhkina, J. Phys. Chem. A 2014, 118, 9745-9752; h) P. O. Adelani, N. A. Martinez, N. D. Cook, P. C. Burns, Eur. J. Inorg. Chem. 2015, 340-347; i) A. V. Savchenkov, V. V. Klepov, A. V. Vologzhanina, L. B. Serezhkina, D. V. Pushkin, V. N. Serezhkin, CrystEngComm 2015, 17, 740-746; j) A. V. Savchenkov, A. V. Vologzhanina, L. B. Serezhkina, D. V. Pushkin, S. Y. Stefanovich, V. N. Serezhkin, Z. Anorg. Allg. Chem. 2015, 641, 1182-1187; k) S. A. Novikov, L. B. Serezhkina, M. S. Grigor'ev, N. V. Manakov, V. N. Serezhkin, Polyhedron 2016, 117, 644-651; I) P. Thuéry, J. Harrowfield, Cryst. Growth Des. 2017, 17, 2881-2892; m) M. Kalaj, K. P. Carter, A. V. Savchenkov, M. M. Pyrch, C. L. Cahill, Inorg. Chem. 2017, 56, 9156-9168; n) C. Liu, C. Wang, Z. M. Sun, Inorg. Chem. 2018, 57, 15370-15378.

[29] J. Han, S. Q. Zang, T. C. W. Mak, Chem. Eur. J. 2010, 16, 5078-5088.

[30] A. Huczyński, J. Janczak, B. Brzezinski, J. Mol. Struct. 2011, 996, 48-52.

[31] P. Comba, W. Schiek, Coord. Chem. Rev. 2003, 238-239, 21-29.

[32] Z. J. Lin, J. Lu, M. Hong, D. Cao, Chem. Soc. Rev. 2014, 43, 5867-5895.

[33] W. M. Bloch, C. L. Sumby, Eur. J. Inorg. Chem. 2015, 3723-3729.

[34] C. R. Murdock, B. C. Hughes, Z. Li, D. M. Jenkins, Coord. Chem. Rev. 2014, 258-259, 119-136.

[35] a) H. F. Zhu, Z. H. Zhang, W. Y. Sun, T. A. Okamura, N. Ueyama, Cryst. Growth Des. 2005, 5, 177-182; b) P. Thuéry, J. Harrowfield, Inorg. Chem. 2016, 56, 6799-6816.

[36] R. W. W. Hooft, COLLECT, Nonius BV: Delft, The Netherlands, 1998. 
[37] Z. Otwinowski, W. Minor, Methods Enzymol. 1997, 276, 307-326.

[38] G. M. Sheldrick, Acta Crystallogr., Sect. A 2008, 64, 112-122.

[39] G. M. Sheldrick, Acta Crystallogr., Sect. A 2015, 71, 3-8.

[40] G. M. Sheldrick, Acta Crystallogr., Sect. C 2015, 71, 3-8.

[41] L. J. Farrugia, J. Appl. Crystallogr. 2012, 45, 849-854.

[42] K. Momma, F. Izumi, J. Appl. Crystallogr. 2011, 44, 1272-1276.

[43] V. A. Blatov, A. P. Shevchenko, D. M. Proserpio, Cryst. Growth Des. 2014, 14, 35763586. 


\section{Dipodal, Tripodal and Discoidal Coordination Modes of Kemp's}

\section{Triacid Anions}

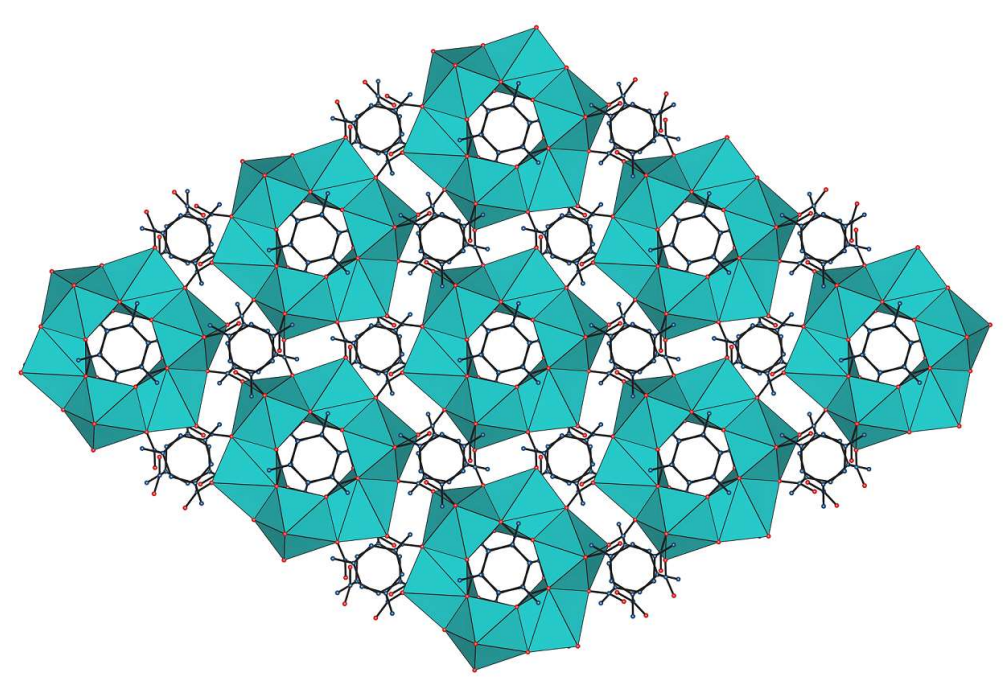

The conformational preferences of the anions derived from Kemp's triacid in their metal ion complexes depend on the nature of the metal cation. The most common form is that of the chair with all carboxylate groups axial (tripodal), but examples are given of the chair form with all groups equatorial (discoidal) and of the rare boat conformation with one axial and two equatorial groups (dipodal). 